\title{
Microsurgical Resection of the Epidermoid Tumor in the Cerebellopontine Angle
}

\author{
Mirza Pojskić ${ }^{1}$ Kenan I. Arnautović 2,3 \\ ${ }^{1}$ Department of Neurosurgery, University of Marburg, Marburg, \\ Germany \\ 2 Semmes Murphey, Memphis, Tennessee, United States \\ ${ }^{3}$ Department of Neurosurgery, University of Tennessee Health \\ Science Center, Memphis, Tennessee, United States
}

\begin{abstract}
Address for correspondence Kenan Arnautović, MD, PhD, Department of Neurosurgery, Semmes Murphey, 6325 Humphreys Boulevard, Memphis, TN 38120, United States (e-mail: kenanarnaut@yahoo.com).
\end{abstract}

J Neurol Surg B 2019;80(suppl S3):S327-S328.

\begin{abstract}
Keywords

- cerebellopontine angle

- epidermoid tumor

- epidermoid tumor cyst

- microsurgery

In this video, we demonstrate epidermoid tumor microsurgical resection of the cerebellopontine angle (CPA) performed by the senior author (K.I.A.). Epidermoid tumors arise from ectoderm trapped within/displaced into the central nervous system. They show predilection for CPA Angle (up to 40\%), 4th ventricle, suprasellar region, and spinal cord. ${ }^{1}$ They are the 3rd most common CPA tumor, comprising approximately 7\% of CPA pathology. CPA lesions can produce 5 th and $7-12$ th cranial nerve neuropathies. ${ }^{2-4}$ Recurrent episodes of aseptic meningitis caused by cyst content rupture may occur. Symptoms include fever, meningeal irritation, and hydrocephalus. A 26-year-old female presented with headaches. Head magnetic resonance imaging (MRI) revealed right CPA tumor with brain stem compression (-Fig. 1, A-C). There was evidence of restricted diffusion in diffusion-weighted imaging, typical of epidermoid tumor. Surgery was performed in prone position with head turned 25 degrees to the ipsilateral side using retrosigmoid craniotomy. ${ }^{5}$ Tumor was ventral to the 7 th and 8 th cranial nerve complexes, between the 5 th nerve as well as toward the brainstem. The surgical plan was gross total resection with tumor capsule resection to prevent recurrence. ${ }^{6}$ (Small residuals can be left behind when capsule is adherent to critical structures.) Tumor was adherent to brain stem perforators which were preserved using meticulous dissection. Cranial nerves and vascular structures were also left intact. We irrigated with antibiotic saline and used perioperative treatment to prevent aseptic meningitis. The pathohistological diagnosis revealed epidermoid tumor cyst. Postoperative MRI revealed complete resection (-Fig. 1, D-F). The patient recovered fully and was neurologically intact.

The link to the video can be found at: https://youtu.be/LyWI-KZUSGY.
\end{abstract}

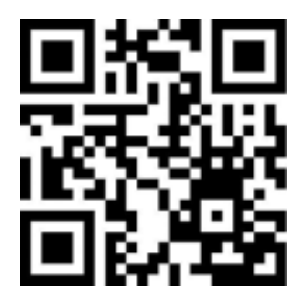

received

April 19, 2018 accepted after revision November 11, 2018 published online January 31, 2019 www.thieme.com/skullbasevideos

www.thieme.com/jnlsbvideos
(C) 2019 Georg Thieme Verlag KG Stuttgart · New York

License terms

10.1055/s-0038-1677499. ISSN 2193-6331.

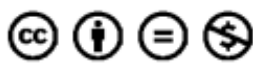



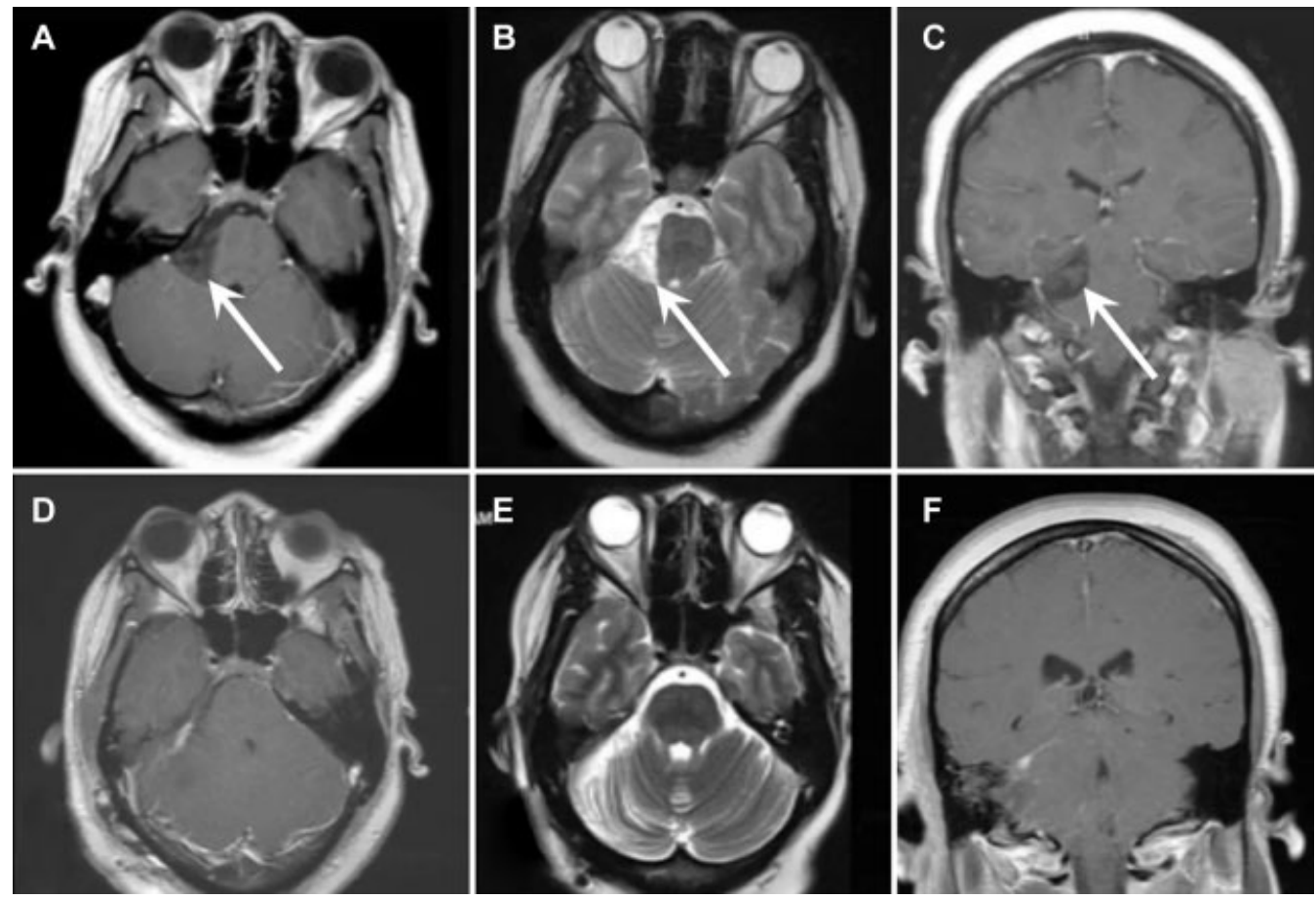

Fig. 1 (A) Preoperative axial MRI, (B) axial diffusion-weighted imaging, and (C) coronal MRI of epidermoid tumor in the right CPA. (D) Postoperative axial MRI, (E) axial diffusion-weighted imaging, and (F) coronal MRI demonstrating complete resection of tumor. CPA, cerebellopontine angle; MRI, magnetic resonance imaging.

Conflict of Interest

None of the authors have any conflicts of interest to disclose. No financial or material support was accepted as part of this study.

\section{Acknowledgements}

The authors wish to thank Andrew J. Gienapp for copy editing, preparation of the manuscript, and figure for publishing, and publication assistance.

\section{References}

1 Yawn RJ, Patel NS, Driscoll CL, et al. Primary epidermoid tumors of the cerebellopontine angle: a review of 47 cases. Otol Neurotol 2016;37(07):951-955

2 Samii M, Tatagiba M, Piquer J, Carvalho GA. Surgical treatment of epidermoid cysts of the cerebellopontine angle. J Neurosurg 1996;84(01):14-19
3 Hasegawa M, Nouri M, Nagahisa S, et al. Cerebellopontine angle epidermoid cysts: clinical presentations and surgical outcome. Neurosurg Rev 2016;39(02):259-266, discussion 266-267

4 Aboud E, Abolfotoh M, Pravdenkova S, Gokoglu A, Gokden M, AlMefty O. Giant intracranial epidermoids: is total removal feasible? J Neurosurg 2015;122(04):743-756

5 Arnautovic KI, Al-Mefty O. Cerebellopontine angle meningiomas. In: Kaye AH, Black PM, eds. Operative Neurosurgery. Vol. 1. London, England: Churchill Livingstone; 2000:545-558

6 Abolfotoh M, Bi WL, Hong CK, et al. The combined microscopicendoscopic technique for radical resection of cerebellopontine angle tumors. J Neurosurg 2015;123(05):1301-1311 